\title{
USE OF THE INTRAMUSCULAR ROUTE FOR PREDNISOLONE ACETATE THERAPY
}

\author{
BY \\ H. F. WEST* \\ Sheffield Centre for the Investigation and Treatment of Rheumatic Diseases
}

There are several ways in which the oral administration of prednisolone may be unsatisfactory:

(1) Once a therapeutic dose of prednisolone has been taken for several weeks, the sudden withdrawal of therapy may have unpleasant consequences. The great majority of patients will stick to the dose ordered, but there are occasions when they may not be able to do so. The commonest involuntary withdrawal occurs during gastro-intestinal upsets, especially those due to poisoning or infection from food, when the tablets may either be vomited or passed through too quickly to be absorbed. Accidents and operations may also lead to a reduction in or cessation of therapy just when a larger dose is necessary. If it were possible to give prednisolone as a depot injection that lasted for one or a number of weeks, such complications might be avoided. A dose missed by a day or two would not result in a sudden deficiency of adrenal hormone and the fact that a dose had been missed would be known to the person responsible for giving the injection.

(2) When prednisolone is given by mouth, the stomach, duodenum, and jejunum absorb a very much higher concentration of the hormone than they normally encounter. The very low incidence of gastric complications encountered during adrenal stimulation therapy (West, 1957) suggests that the dyspepsia, stomach cramps, and peptic ulceration which are too common with oral cortisone or prednisolone therapy may result from a local action on the digestion tract. The giving of prednisolone by intramuscular injection might obviate much of this trouble.

(3) Prednisolone administered orally has also to pass through the liver in relatively high concentration, and two unwanted effects may result:

\footnotetext{
- Physician-in-charge and part-time Nuffield Research Fellow, University of Sheffield.
}

(i) Some aspect of liver function may be upset.

(ii) The liver may acquire an enhanced ability to destroy the hormone.

With regard to the former, at this Centre we have reason to suspect that amyloid formation in the liver is, to say the least, not favourably affected by orally administered corticosteroids. For the latter there is no supporting evidence but it is clear that an adaptation to prolonged oral corticosteroid therapy occurs somewhere.

In view of these considerations it was decided to explore the use of intramuscular prednisolone acetate therapy. At the right moment, Pfizers came forward with a very generous supply of Deltacortril (prednisolone acetate) suspension which they were anxious that we should study using the intramuscular route.

Before embarking on this investigation certain questions had to be asked and answered:

(1) How quickly will the intramuscular prednisolone acetate produce its effects? It was found that this depended upon the size of the dose given and the need of the patient. If a patient needed very little added cortisone-like steroid to produce a therapeutic effect, an intramuscular injection of $25 \mathrm{mg}$. prednisolone acetate (Deltacortril) would produce noticeable effects in 3 to 4 hours. If, on the other hand, the patient was accustomed to $15 \mathrm{mg}$. oral prednisolone daily, an abrupt change to a single daily injection of $25 \mathrm{mg}$. prednisolone acetate would result in a temporary relapse. The cumulative effect of the daily injections might take 3 to 4 days to restore the previous state.

(2) Is a given dose of prednisolone acetate more, or less, effective when given by intramuscular injection? Animal studies had suggested that it was less effective by intramuscular injection, and this is what we thought at first, but with repeated injections a 
cumulative effect became apparent and the intramuscular dose became as effective as the oral.

(3) How long does a given injection remain effective? This too was found to depend upon the size of the dose and the need of the patient. The problem can be reviewed in diagrammatic form. In the Figure, " $A$ " represents a previously untreated patient with a low blood concentration of circulating adrenal hydrocortisone; " $B$ " represents a similar patient with an average normal concentration; " $\mathrm{C}$ " a patient accustomed to $15 \mathrm{mg}$. oral prednisolone daily; "D" a patient accustomed to $20 \mathrm{mg}$. daily. The shape of the curve for the effective prednisolone concentration following the intramuscular injection has been deduced partly from clinical and partly from urinary corticosteroid assay findings. It will vary a little from patient to patient, the rate of absorption being no doubt affected by the vascularity of the site of the depot and by any local reaction that may occur. It will be appreciated that to treat patient " $D$ ", who is being changed from a high oral dose of prednisolone, the injections will have to be repeated every 4 to 5 days to build up an effective concentration. Patient " $C$ " will be without benefit on the first day but will possibly be maintained on Days 2 and 3. Patient "B" will benefit for about 6 days, and Patient " $A$ " for 2 or 3 days longer.

(4) Will abscess formation occur? One of the complications of the original cortisone acetate therapy was abscess formation. The same complication has occurred with intramuscular prednisolone acetate injections, but no abscesses have resulted from injections given by our in-patient or out-patient nursing staff. The abscesses that form are clearly due to faulty technique, a technique that no doubt rarely causes trouble with other medicaments. The abscesses cause little pain or induration and may attain a great size with little tendency to point. When incised they heal readily. Staphylococci were cultured from the abscesses we encountered.

\section{Patients}

The patients treated fell into two groups:

(a) Those with severe, long-standing disease, who had received oral steroid therapy for several years and who were in trouble from gastro-intestinal and other complications,

(b) Those who had had little or no previous steroid therapy.

To a Centre specializing in the treatment of rheumatoid arthritis the most difficult therapeutic problems gravitate from far and wide, and most of the patients treated presented difficult problems. The brief case reports which follow start with th 8 simple and proceed to the complex problems. The letters PAIM are used to denote prednisolone acetate suspension (Deltacortril Pfizer) by intra muscular injections.

\section{$100 \mathrm{mg}$. INTRAMUSCULAR PREDNISOLONE ACETATE}

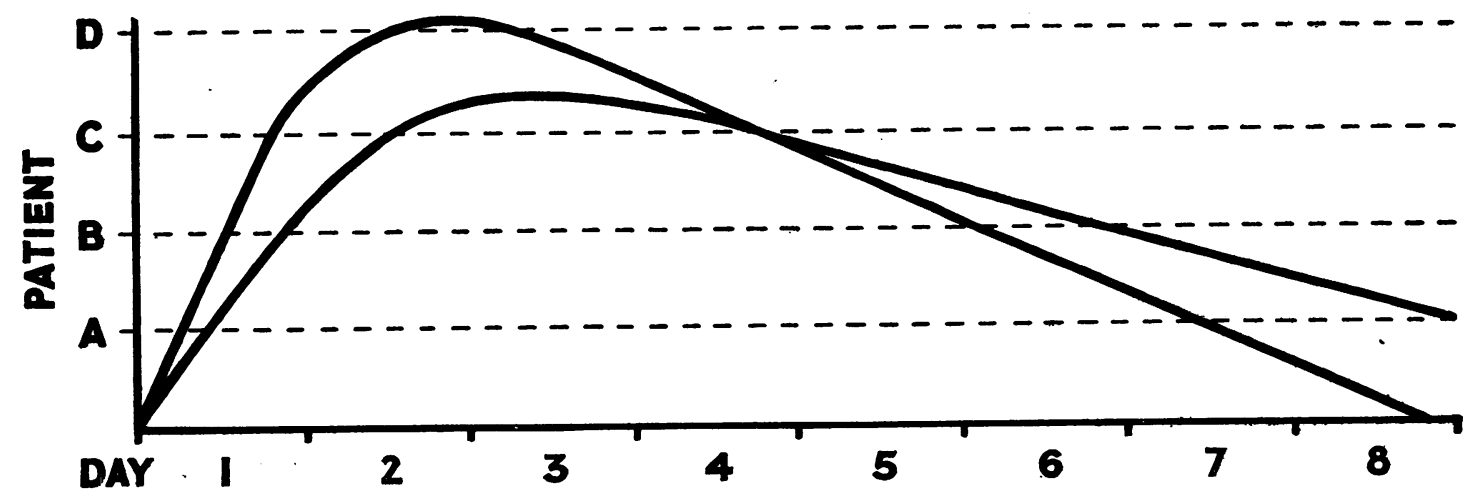

Figure.-Effective blood concentration of prednisolone, deduced from clinical and urinary corticosteroid assay data, following intramuscular injection of $100 \mathrm{mg}$. prednisolone acetate (Deltacortril suspension).

Patient $A$ has a low level of circulating cortisol and excretes approximately $7 \mathrm{mg}$. of total 17-hydroxycorticosteroids daily. Patient B excretes approximately $12 \mathrm{mg}$. of total 17-hydroxycorticosteroids.

Patient $C$ is on a maintenance dose of $15 \mathrm{mg}$. prednisolone given orally.

Patient $D$ is on a maintenance dose of $20 \mathrm{mg}$. prednisolone given orally. 


\section{Case Reports}

Case 1, a male aged 36, had rheumatoid arthritis for 6 months, and was unable to continue work (he was self-employed).

He was given $80 \mathrm{mg}$. PAIM once each week for 25 weeks. He was occasionally stiff on Day 7, but otherwise without signs or symptoms of rheumatoid arthritis and able to work full time. He had no digestive disturbance.

Case 2, a female aged 43, had rheumatoid arthritis for 1 year, and had received phenylbutazone $3 \times 100 \mathrm{mg}$. for 1 year. The disease activity was widespread and her grip was too weak for her to continue at work.

She was given $80 \mathrm{mg}$. PAIM once each week for 30 weeks. She had no symptoms for 20 weeks, but now has some stiffness on Days 6 and 7. She is working normally, and has no digestive disturbance.

Case 3, a male aged 50, had rheumatoid arthritis for 12 years, with a long history of recurrent dyspepsia. He had previously received cortisone and prednisolone for 1 year, and his condition was unsatisfactory on $15 \mathrm{mg}$. prednisolone by mouth.

He was given 80 to $100 \mathrm{mg}$. PAIM weekly for 28 weeks, with almost complete relief of symptoms. He is working normally, and has no digestive disturbances.

Case 4, a female aged 46, had rheumatoid arthritis for 9 years, and myxoedema for 4 years. Prednisolone $10 \mathrm{mg}$. for 1 year had been satisfactory, but there was a previous history of duodenal ulcer.

She was given PAIM 80 to $70 \mathrm{mg}$. weekly for 25 weeks. She is symptom free, and has no digestive disturbance.

Case 5, a male aged 56, had rheumatoid arthritis for 5 years. Aspirin therapy (in the Aspirin/Cortisone Trial) for 4 years had ended in gross deformity, so that he was unable to work. Adrenal stimulation therapy for 15 months had restored his health and earning capacity.

Because of breathlessness on exertion (chronic bronchitis) he was given PAIM $80 \mathrm{mg}$. weekly for 13 weeks. The arthritis was well controlled but breathlessness on exertion returned, and he has now been changed to Triamcinolone.

Case 6, a female aged 61, had rheumatoid arthritis for 11 years, with gross deformity and much pain. Prednisolone $10 \mathrm{mg}$. orally for 4 months had given major relief but dyspepsia began and in spite of antacid therapy a gastric haemorrhage occurred.

The prednisolone was stopped, and after 2 months of dependence on others for personal needs she was given PAIM $80 \mathrm{mg}$. weekly for 25 weeks. She is now able to look after herself, and has no dyspepsia.

Case 7 , a female aged 55, had rheumatoid arthritis for 7 years. She had received hormone therapy for 5 years, but had developed a duodenal ulcer with persistent symptoms for last 2 years.

She was given PAIM $80 \mathrm{mg}$. weekly for 25 weeks. The ulcer symptoms went immediately but returned after several weeks. They persisted in spite of all treatment until she went on holiday, when they finally disappeared.

Case 8, a male aged 50, had rheumatoid arthritis for $3 \frac{1}{2}$ years. The disease was not controlled by aspirin or phenylbutazone, and he was given adrenal stimulation therapy for 15 months followed by 1 year on prednisolone $15 \mathrm{mg}$. daily. During the prednisolone therapy a gastric ulcer developed and a haemorrhage occurred; the prednisolone was continued but severe pain recurred.

He was given PAIM $40 \mathrm{mg}$. every other day and later $60 \mathrm{mg}$. every 4 days for 32 weeks. The gastric symptoms disappeared immediately but dyspepsia recurred after 8 weeks and has recurred intermittently ever since.

Case 9, a female aged 62, had rheumatoid arthritis for 34 years, and myxoedema for 4 years. She had had steroid therapy for 5 years, and a severe relapse occurred while she was on $15 \mathrm{mg}$. prednisolone.

She was given PAIM $60 \mathrm{mg}$. every 3 days and later every 4 days for 20 weeks. Recovery was rapid but there was some relapse after 12 weeks. She has no digestive disturbance.

Case 10, a male aged 41, had rheumatoid arthritis for 5 years. He had had steroid therapy for $4 \frac{1}{2}$ years, and for the last year prednisolone 12.5 to $15 \mathrm{mg}$. daily.

Weakness, dyspepsia, loss of appetite, and early signs of peripheral neuritis (in the feet and ankles) prompted a change to PAIM $40 \mathrm{mg}$. daily, which was slowly reduced to $80 \mathrm{mg}$. weekly for 42 weeks. His strength and appetite are restored, and he is back at work, but latterly epigastric pain of the duodenal ulcer type has recurred intermittently.

Case 11, a female aged 35, had rheumatoid arthritis for 7 years with bronchiectasis. The arthritis was widespread with gross damage in hips and knees. She had had steroid therapy for 4 years, prednisolone $15 \mathrm{mg}$. daily for the last 2 years, and had experienced recurring nausea and heartburn.

She was given PAIM 60 mg. every 3 days, for 16 weeks. There has been no digestive disturbance in spite of this excessive steroid therapy, which is to be reduced.

Case 12, a female aged 42, had rheumatoid arthritis for 11 years, with recurrent thyrotoxicosis. She had received steroid therapy for 7 years, and had latterly been given 10 to $12.5 \mathrm{mg}$. prednisolone.

A change to PAIM was made because of repeated attacks of abdominal pain and diarrhoea and loss of appetite. The basal metabolism rate was +25 , and she was too stiff to do any housework. She received PAIM $40 \mathrm{mg}$. every other day slowly reduced to $40 \mathrm{mg}$. every 4 days for 39 weeks. She recovered rapidly and returned to work. Hypertension developed on the high dose but has fallen with decreasing dosage. On the present dose she has some stiffness on Day 4, but there is no need for anti-thyroid therapy, and no digestive disturbance.

Case 13, a male aged 51, had rheumatoid arthritis for 10 years. The disease was active and widespread 
with much damage. He had received steroid therapy for 4 years (at a high level but the exact dose is not known). He had suffered prolonged dyspepsia.

He was given PAIM $20 \mathrm{mg}$. daily for 12 weeks. A major improvement after 4 weeks was followed by a heavy fall and a relapse, and after 12 weeks peripheral neuritis developed. There was no digestive disturbance while he was receiving PAIM.

Case 14, a female aged 45 , had rheumatoid arthritis for 9 years. The disease was widespread with gross damage in hips and knees. She had received steroid therapy for $4 \frac{1}{2}$ years.

PAIM therapy was started during a period of depression; she received $60 \mathrm{mg}$. every 3 days for 30 weeks. Subjective and objective improvement was due to relief of an unrelated emotional problem. She developed hypertension because the dosage of PAIM was excessive, and was changed to Triamcinolone. There was no digestive disturbance.

Case 15, a female aged 34 , had rheumatoid arthritis for 11 years. The disease was widespread with gross damage of hips and knees. She received steroid therapy for $4 \frac{1}{2}$ years, and severe gastric haemorrhage necessitated partial gastrectomy while on prednisolone. She was unable to dress or do light housework.

Because of recurring gastro-intestinal upset and vomiting she was given PAIM $40 \mathrm{mg}$. every other day for 22 weeks. The gastric symptoms disappeared at once and did not recur, and she was able to dress herself and be of use in the house and shop. The therapy was changed to Triamcinolone because of oedema of the legs, and 2 weeks later gastric symptoms recurred.

Case 16, a male aged 40, had severe ankylosing spondylitis for 14 years, involving the hips (which were destroyed) and knees as well as the whole spine.* $\mathrm{He}$ had received steroid therapy for $6 \frac{1}{2}$ years, latterly $12.5 \mathrm{mg}$. prednisolone.

Severe dyspepsia, loss of appetite, impotence, and the appearance of a large amyloid liver prompted a change to PAIM $40 \mathrm{mg}$. every other day, reduced to $50 \mathrm{mg}$. every 3 days, for 45 weeks. There was a major improvement in strength, and he was able to return to work. His appetite returned and the dyspepsia disappeared. After 4 to 5 months the dyspepsia and melaena recurred, but for the last 3 months all has been well.

\section{Other Findings}

Erythrocyte Sedimentation Rate.-A fall occurred in most patients, as would be expected with the increase in effective dosage that most patients received.

Haemoglobin.-No significant change.

Total White Blood Count.-Tendency to rise.

Strength of Grip.-Major increase in most patients.

Weight.-Some rise in patients receiving more than $100 \mathrm{mg}$. PAIM each week.

- The patient's brother had had every joint in his body and his eyes destroyed by ankylosing spondylitis and had died of amyloidosis
Blood Pressure.-Significant rise in Cases 11, 12, and 14 while receiving a high dosage.

Moonface.-Noticeable in women receiving $100 \mathrm{mg}$. or more each week.

\section{Discussion}

It should be emphasized again that most of the patients treated were problem cases gathered together from some 4,000 rheumatoid arthritics treated in recent years. It is apparent that, if one wants or needs to give prednisolone by intramuscular injection over prolonged periods, Deltacortril suspension (Pfizer) is suitable and convenient. The present preparation is a little bulky as it contains only $20 \mathrm{mg}$. per $\mathrm{ml}$., but more concentrated suspensions that are absorbed at a suitable rate will no doubt be forthcoming. Two preparations of prednisolone containing $100 \mathrm{mg}$. per $\mathrm{ml}$. have been tried, but they have been found satisfactory in only a minority of patients. In one patient a single injection of $400 \mathrm{mg}$. remained effective for more than 3 weeks. Preparations of cortisone acetate and of Triamcinolone prepared for intra-articular injection were absorbed too fast by intramuscular injection for weekly maintenance therapy.

Our experience of the difficult patients described above leaves no doubt that intramuscular pred-o nisolone is of real value in preventing or minimizing the gastro-intestinal disturbances that occur witho oral therapy. The marked improvement in health of Case 16 with a large amyloid liver on changing from oral to intramuscular prednisolone is worthy of note. It will take a year or two to find out whether intramuscular prednisolone will remain effective for a longer time than oral prednisolone. Systemically administered cortisol, produced by adrenal stimulation, certainly remains effective for a much longer period than oral cortisone acetate (West, 1957). It was hoped that, by using the intramuscular route and avoiding the liver, some of the side-effects might have been less. So far this has not proved to be the case, though there has been less weight gain than expected. The need to keep the dosage down to safe levels remains. This is easy to say but difficult to practise with the 1 per cent. of rheumatoid arthritics who run a prolonged severe course.

\section{Summary}

Intramuscular prednisolone acetate (Deltacortril suspension Pfizer) has been given for periods of from 16 to 45 weeks to sixteen patients suffering from severe rheumatoid arthritis. A weekly depot injection was found to be satisfactory. Certain advantages attend this route of prednisolone administration, including, in particular, a marked 
lessening of gastric disturbance. Other benefits may become apparent during long-term therapy.

Grateful thanks are due to Dr. G. R. Newns and Dr. H. W. Fladee for much clinical help and to the nursing staff of this Centre for their indispensable service.

\section{REFERENCE}

West, H. F. (1957). Ann. rheum. Dis., 16, 322.

\section{L'acétate de prednisolone par voie intramusculaire} RÉsumÉ

On administra de l'acétate de prednisolone (Deltacortril suspension, Pfizer) par voie intramusculaire pendant des périodes de 16 à 4.5 semaines à 16 malades atteints d'arthrite rhumatismale sévère. On trouva qu'une injection de depôt par semaine fut satisfaisante.
Cette voie d'administration de la prednisolone présente certains avantages, y compris, en particulier, une diminution marquée des troubles gastriques. D'autres avantages pourraient apparaître si l'on prolongait le traitement.

\section{El acetato de prednisolona por vía intramuscular} SUMARIO

Acetato de prednisolona (Deltacortril suspensión, Pfeizer) fué administrado por vía intramuscular durante períodos de 16 a 45 semanas a 16 enfermos con artritis reumatoide severa. Una inyección de depósito por semana dió resultados satisfactorios. Esta vía de administración ofrece ciertas ventajas, incluso, en particular, la disminución marcada de disturbios gástricos. Otras ventajas pudieran evidenciarse con un tratamiento más prolongado. 